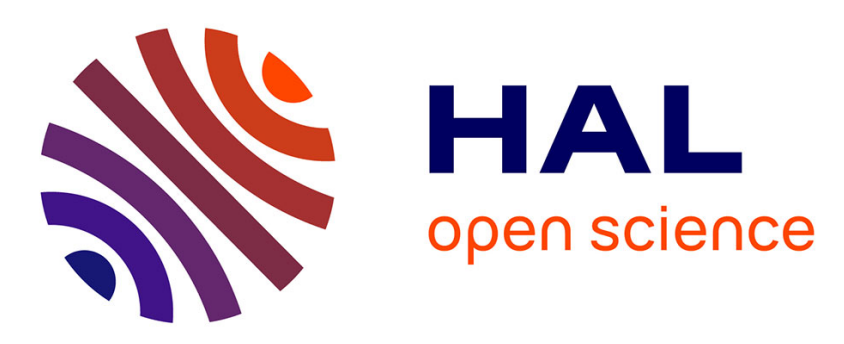

\title{
Evaluation of the structure and dispersion in polymer-layered silicate nanocomposites
}

Alexandre Vermogen, Karine Masenelli-Varlot, Roland Seguela, J.

Duchet-Rumeau, S. Boucard, P. Prele

\section{- To cite this version:}

Alexandre Vermogen, Karine Masenelli-Varlot, Roland Seguela, J. Duchet-Rumeau, S. Boucard, et al.. Evaluation of the structure and dispersion in polymer-layered silicate nanocomposites. Macromolecules, 2005, 38 (23), pp.9661-9669. 10.1021/ma051249+ . hal-00436875

\section{HAL Id: hal-00436875 \\ https://hal.science/hal-00436875}

Submitted on 13 Jun 2019

HAL is a multi-disciplinary open access archive for the deposit and dissemination of scientific research documents, whether they are published or not. The documents may come from teaching and research institutions in France or abroad, or from public or private research centers.
L'archive ouverte pluridisciplinaire HAL, est destinée au dépôt et à la diffusion de documents scientifiques de niveau recherche, publiés ou non, émanant des établissements d'enseignement et de recherche français ou étrangers, des laboratoires publics ou privés. 


\title{
Evaluation of the Structure and Dispersion in Polymer-Layered Silicate Nanocomposites
}

\author{
Alexandre Vermogen,* Karine Masenelli-Varlot,* and Roland Séguéla \\ Groupe d'Etudes de Métallurgie Physique et de Physique des Matériaux, UMR CNRS 5510, \\ INSA de Lyon, Bât. B. Pascal, 7 Avenue Jean Capelle, 69621 Villeurbanne Cedex, France \\ Jannick Duchet-Rumeau \\ Laboratoire des Matériaux Macromoléculaires, UMR 5627-IMP, INSA de Lyon, Bât. Jules Verne, \\ 69621 Villeurbanne Cedex, France \\ Sylvain Boucard and Patrick Prele \\ Multibase Dow Corning, Z.I. Chartreuse-Guiers, 38380 Saint-Laurent-du-Pont, France \\ Received June 14, 2005; Revised Manuscript Received August 30, 2005
}

\begin{abstract}
Polymer-layered silicate nanocomposites have drawn a great interest in polymer science these past years. Understanding of the complex mechanism of dispersion and exfoliation of the clay tactoids may allow us to better control the final morphology and the homogeneity of clay nanocomposites and thus their macroscopic properties. The first step we propose in this study consists of a multiscale approach of the exfoliation state of the extruded polypropylene/montmorillonite nanocomposite. We used three extruders designs: a single-screw extruder, a twin-screw extruder, and an optimized-screw extruder with adapted shear. The rheological analysis, the WAXS diffractograms, and the TEM micrographs all show different nanocomposite morphologies. A statistical TEM image analysis methodology was developed to evaluate the different particle parameters (thickness, length, aspect ratio, interparticle distance). The results obtained show a correlation between the size of the tactoids and the shear intensity.
\end{abstract}

\section{Introduction}

Work in polymer nanocomposites has exploded over the past few years. These materials, with features on the nanometer scale, often exhibit properties superior to their macroscale counterparts. Though significant progress has been made in developing nanocomposites with different polymer matrices, ${ }^{1-3}$ a general understanding has yet to emerge. For example, how can we use specific molecular interactions or precise mixing conditions to control the structure and the morphology? How can materials properties be predicted from nanostructural data?

Among these new nanostructured materials, montmorillonite is often used as layered inorganic nanoparticles. Montmorillonite is a 2:1 phyllosilicate; its crystalline structure consists of two-dimensional layers composed of two tetrahedral sheets of silica surrounding an octahedral sheet of alumina or magnesia. Each individual layer is about $1 \mathrm{~nm}$ thick and around 500 $\mathrm{nm}$ width. The main advantages of montmorillonite are its low cost, a great potential specific area $\left(700 \mathrm{~m}^{2} / \mathrm{g}\right)$, a high aspect ratio (100), and good swelling properties. When dispersed homogeneously in a polymer matrix, at very low weight ratio, the nanolayers can greatly enhance thermal stability as well as mechanical and barrier properties, as reported in the literature., ${ }^{1,4-14}$

Many traditional routes are used for processing polymer montmorillonite nanocomposites. ${ }^{1,4}$ During the elaboration process, the interactions between the matrix and the clay layers are essential. In some cases, to improve the intercalation/exfoliation of the polymer chains in the interlayer, it is possible to swell montmorillonite with quaternary ammonium ions or to add a

\footnotetext{
* Corresponding authors. E-mail: alexandre.vermogen@ insa-lyon.fr; Karine.Masenelli-Varlot@insa-lyon.fr.
}

coupling agent functionalized with more polar groups like maleic anhydride groups in a quite hydrophobic polyolefin matrix. For example, results reported by Beyer et al. ${ }^{15}$ reveal a better intercalation of maleic anhydride grafted polyethylene and polypropylene (PEgAM and PPgAM) nanocomposites by increasing the length of the surfactant ion chains. In another work, Dennis et al. ${ }^{3}$ studied the morphologies of polyamide nanocomposites vs process conditions. They showed that there was an optimum in dispersion and exfoliation state for a mean residence time and for an optimized shear, not necessarily the highest ones.

The properties achieved by nanocomposites are often related to their structures and to the states of dispersion of the tactoids in the polymer matrix. The works of Liu et al. ${ }^{8}$ and Liang et al. ${ }^{9,10}$ clearly correlate the state of exfoliation, the structure, and the mechanical reinforcement. They identified a critical weight ratio threshold where the nanostructure jumps from an exfoliated state, at low weight ratio, to a mixed state (exfoliated/ intercalated) at higher weight ratio. These results show the importance of having a good knowledge of the studied system. On the basis of simple cases in layered silicate nanocomposites, three layer organizations can be differentiated. ${ }^{1}$ In the case of low interactions and/ or bad shearing conditions, the clay layers form an immiscible phase, i.e., micron size agglomerates, in the polymer matrix. This system is thus equivalent to a traditional microcomposite. The intercalated nanostructure is described when a few polymer chains are able to diffuse in the interlayer space. When all the layers are homogeneously dispersed as single layers in the matrix, the nanostructure is called exfoliated.

To describe the state of exfoliation and intercalation, two analysis tools are widely used because the results obtained by these techniques are quite easy to interpret. ${ }^{1,3,4,12,16-18}$ The evolution of the interlayer distance 
can be followed by X-ray diffraction (WAXS), but in some cases (for example, a random orientation of the layers, a large amount of clay, an inhomogeneous distribution of surfactant in the interlayer space, or a distribution of interlayer distance), it can lead to a false and incomplete interpretation of the nanostructure. For these reasons, many authors ${ }^{4,19-21}$ suggest to compare the results obtained by WAXS with direct observations of the clay layers by transmission electron microscopy (TEM). The main problem of TEM is that the volume probed is very small and may not be representative of the nanocomposite in its whole.

In practice, the organization of the clay layers in the matrix is more complicated. . $^{3,18,19,21}$ The concept of order/ disorder has to be introduced, and the coexistence of exfoliated, intercalated, and immiscible clay layers morphologies categories (as first determined by X-ray diffraction and transmission electron microscopy) was not fully taken into account. New works begin to quantify these differences of nanostructures, orientations, and dispersions to get a better knowledge of the morphologies of the nanocomposites.

Bafna et al. ${ }^{22}$ recently reported the use of the Wilchinsky diagram construction, a method used for the calculation of the 3D orientation of the crystalline lamellae, to determine the differences in the orientation of the clay layers in polyethylene cast films with different amounts of maleated polyethylene compatibilizer. With 2D wide-angle X-ray scattering and 2D small-angle $\mathrm{X}$-ray scattering, they were able to differentiate the orientations of different entities such as clay clusters/ tactoids $(0.12 \mu \mathrm{m})$, modified (intercalated) clay, unmodified stacks of clay, and crystalline lamellae. Their results mainly show that there was not an homogeneous orientation of the clay layers in the matrix. In particular, they observed a high orientation of the clusters and intercalated clay in the film plane, i.e., along the shear field, and no preferential orientation of the unmodified stack of clays. However, no information was given about the correlation of the results with the width of the entities. Other studies ${ }^{23-25}$ showed that there was a relationship between the layers orientation and the crystalline orientation. All the approaches listed here are very interesting because the evolution of the crystalline morphology seems to be related with the layers orientation.

Other articles from the literature describe rheology ${ }^{19,26-28}$ as a potential technique for the evaluation of the nanostructure and dispersion. The increase of complex viscosity at low shearing rates is significant of a good dispersion state of layers. ${ }^{19,26}$ The dispersion of clay in the matrix in the molten state is due to both macroscopic and local shearing, ${ }^{26}$ which results of the stress transfer of the molten polymer to the silicate layers. In a first part, the shearing tool let the agglomerates peel, and in a second part, local shearing due to the viscosity of the matrix let the polymer chains intercalate in the interlayer space. These different rheological behaviors at low shear, thus states of exfoliation and dispersion, were confirmed by direct transmission electron microscopy and scanning electron microscopy observations. ${ }^{19,26}$

Moreover, a few authors carried out small-angle X-ray scattering 24,29 and nuclear magnetic resonance investigations $^{30,31}$ to study the dispersion and the sizes of the different clusters present in the matrix. For example, in the work of Varlot et al., ${ }^{24}$ they were able to estimate

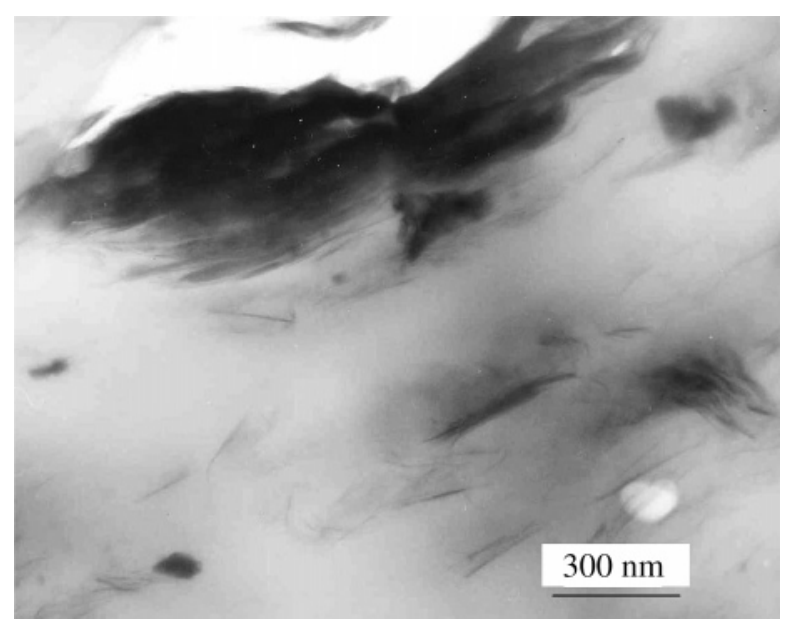

Figure 1. Illustration of the coexistence of micron size agglomerates and isolated single clay sheet on a TEM micrograph of a PP nanocomposite with 5\% clay.

by SAXS an average distance between the montmorillonite exfoliated layers $(3.5 \mathrm{~nm})$ and also the thickness of a single layer $(0.7 \mathrm{~nm})$. These results were also confirmed by transmission electron microscopy. On the other hand, VanderHart et al. ${ }^{30,31}$ have worked about the quantification of the clay platelets dispersion by using nuclear magnetic resonance in the solid state because NMR is sensitive to the longitudinal relaxations of the $\mathrm{Fe}^{3+}$ ions present in the silicate layers. The longitudinal relaxations of $\mathrm{Fe}^{3+}$ are dependent on their concentration and on the distance between particles, i.e., on the dispersion of the clay. Authors highlighted with this technique that increasing the shearing intensity during the extrusion process lead to thinner tactoids and better dispersion of the layers.

Last, Dennis et al., ${ }^{3}$ Nam et al., ${ }^{16}$ VanderHart et al., ${ }^{31}$ Ranade et al., ${ }^{32}$ Marchant et al., ${ }^{33}$ Chavarria et al., ${ }^{34}$ and Fornes et al..$^{35}$ used TEM image analysis to characterize the level of dispersion of the particles in the nanocomposites. They generally calculate the average thickness and length of the tactoids, the interparticular distance, and the average number of platelet per tactoid, and they evaluate the quantity of distinguishable clay entities in the matrix. All these last pieces of information are of real importance as they influence the final properties of the nanocomposite.

Today's limiting factor for the development of nanocomposites is the control the state of exfoliation and its homogeneity as well as the dispersion and the orientation of the layers or the orientation of the polymer crystalline lamellae. The purpose of this work is to propose a novel method based on transmission electron micrographs for evaluating the structure and the state of dispersion of the silicate layers in a polymer matrix. We mainly carried out this methodology on polypropylene-montmorillonite extruded nanocomposites. We used two different organo-modified montmorillonite and three different screw configurations in order to generate different morphologies. An image analysis procedure was developed in order to have a better comprehension of the mechanism of clay dispersion in the melt and also to understand the relationships between the nanostructure and the thermal and mechanical properties enhancement. The reason why we elaborated such a procedure is easy to understand and can be summarized in the TEM micrograph, Figure 1, where we can see the coexistence of tactoids of different thicknesses. We need 
Table 1. Materials Description

specification

PP10 (HV001)

PPNC-C

PPNC-S

PPNC-MIX
$\mathrm{MFI}=10, M_{\mathrm{n}}=31000 \mathrm{~g} / \mathrm{mol}, I_{\mathrm{p}}=12.8$

single-screw extruder carrying screw profile

twin-screw extruder shearing screw profile

twin-screw extruder optimized screw profile supplier

Solvay

75\% PP10, 20\% HMPPgMA, 5\% DT-36

$75 \%$ PP10, 20\% HMPPgMA, 5\% DT-36

75\% PP10, 20\% HMPPgMA, 5\% DT-28 to quantify the proportion of each class of tactoids and to determine the parameters describing the morphology of the particles with an appropriate statistical tool, if we want to efficiently model the properties of such nanocomposites.

\section{Experimental Section}

Materials. The materials used in this study are described in Table 1 . The base polypropylene had a weight-average of $31000 \mathrm{~g} / \mathrm{mol}$ and was provided by Solvay. To ensure a better interaction between the clay and the polypropylene, maleated polypropylene, provided by Dupont (MD353D), was used. ${ }^{36,37}$ The two montmorillonites supplied by Süd Chemie are modified with the same modifying ion, i.e., dimethyl ditallow alkylammonium, in a similar ratio (36\% for DT36 and 33\% for DT28) but show different interlayer distances, $28 \AA$ for DT28 and 36 A for DT36. The processed blends were composed of $75 \%$ of pure polypropylene, $20 \%$ of maleated polypropylene, and $5 \%$ of organophilic montmorillonite. Compounds were realized by melt intercalation on a pilot twin-screw extruder, with a diameter of $25 \mathrm{~mm}$, a length equivalent to $48 \mathrm{D}$, and a rate of $50 \mathrm{~kg} / \mathrm{h}$. The temperature is kept between 180 and 210 ${ }^{\circ} \mathrm{C}$ (from feeder to die); screw speed values are included between 70 and $100 \mathrm{rpm}$ in order to keep the machine torque constant at $90 \%$ of the maximum extruder torque.

To study the effect of processing conditions, three screw profiles were studied showing different carrying/shear ratio: (i) a totally carrying profile from a single screw (C), (ii) a totally shearing profile from a twin screw (S), and (iii) an optimized profile (Mix) developed by Multibase Dow Corning. ${ }^{38}$ Nanocomposite denomination will be respectivly PPNC-C, PPNC$\mathrm{S}$, and PPNC-Mix for each screw design.

Characterization. X-ray scattering (WAXS) were performed at room temperature on a Siemens D500 diffractometer with a back monochromator and a $\mathrm{Cu}$ anticathode. The $2 \theta$ angles varied from $1^{\circ}$ to $10^{\circ}$ at a scanning speed of $0.6^{\circ} / \mathrm{min}$ by step of $0.02^{\circ}$ in order to measure the $d_{001}$ spacing between platelets. The interlayer distance was calculated using Bragg's law, at the maximum of the peak intensity. Rheological measurements were performed on a Rheometrics dynamic analyzer RDA II, using a $25 \mathrm{~mm}$ plate-plate geometry from 0.1 to $100 \mathrm{rad} / \mathrm{s}$ and an applied strain of $10 \%$ at $180{ }^{\circ} \mathrm{C}$.

Optical microscopy observations were carried out on a Zeiss microscope at low magnification $(\times 30)$. The aim of these observations was to check the presence of large agglomerates in the matrix. For these observations, the samples were pressed at $225{ }^{\circ} \mathrm{C}$ during $1 \mathrm{~min}$, kept under pressure at room temperature for $1 \mathrm{mn} 30$ and then cooled at room temperature.

For transmission electron microscopy observations, the same pressed samples were embedded in an epoxy (Epofix) resin. As the montmorillonite particles tend to lie parallel to the film surface, the samples were cut (with an ultramicrotome Reichert $\mathrm{S}$ ) in order to observe the particles on their edges. To obtain sections thin enough and to avoid distortions such as thickness ripples, the surface of the pyramid was roughly set to $0.1 \times 0.1 \mathrm{~mm}^{2}$, and a $35^{\circ}$ diamond knife was used. The temperature was set at $-130{ }^{\circ} \mathrm{C}$, the knife speed to $1 \mathrm{~mm} / \mathrm{s}$, and the thickness to $60 \mathrm{~nm}$. Finally, the sections were mounted on a 400 mesh copper grid. The TEM bright field observations were performed on a JEOL-200CX ( $\mathrm{LaB}_{6}$ filament) microscope operating at $200 \mathrm{kV}$. Observing the layers edge-on was found to be the most convenient configuration for estimating their dimensions, although a small inclination of the layers can lead to variations of the particle dimensions on the projected image. ${ }^{39}$

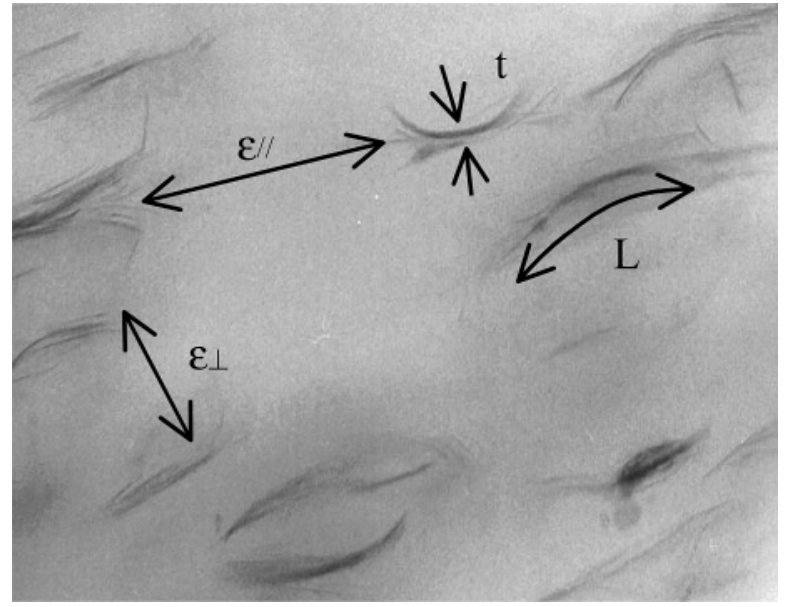

Figure 2. Description of the collected data,

\section{Description of the Image Analysis Procedure}

The observations were realized at three different magnifications, namely $\times 10000, \times 50000$, and $\times 100000$. One micrograph was taken at $\times 10000$, four at $\times 50000$, and 10 at $\times 100000$ in order to have a good overview of the organization of the layers tactoids at different scales. The TEM micrographs were scanned with a resolution of 300 dpi and recorded on a 12 bit gray scale with an appropriated contrast. EsiVision software was used to measure manually the particle curved length $(L)$, thickness $(t)$, and the interparticular distance in the direction parallel to that of the lengths of the tactoids $\left(\epsilon_{\|}\right)$and perpendicular to the latter orientation $\left(\epsilon_{\perp}\right)$, as shown in Figure 2.

To estimate at best the sizes and proportion of clay tactoids in the matrix, we applied several corrections: (i) First, to take into account the fact that the weight of a single platelet is not the same than that of an agglomerate, the number of platelets is calculated using the formula

$$
N_{\text {pi }}(t)=\left(t_{\text {particle }}+d_{001}-t_{\text {platelet }}\right) / d_{001}
$$

where $N$ is the number of platelet per particle, $t_{\text {particule }}$ is the thickness of the particle measured by TEM, $d_{001}$ is the interlayer distance measured by WAXD or TEM and $t_{\text {platelet }}$ is the estimated thickness of a single platelet (about $0.94 \mathrm{~nm}^{34}$ ). (ii) Also, the quantification has to be corrected from the analyzed area, which is different from one magnification to another. Indeed, the area analyzed at a $\times 10000$ magnification contains 100 times more pieces of information than at $\times 100000$. (iii) Finally, to easily compare different nanocomposites, we defined six classes of tactoids according to their thicknesses, as described in Figure 3. We particularly drew our attention to distinguish micron size agglomerates from tactoids of smaller size, which we further called nanotactoids. Since the volume analyzed by TEM is small, only a few micron size agglomerates can usually be detected. This may be non significant of the materials. Thus, the proportion of micron size agglomerates had to be 


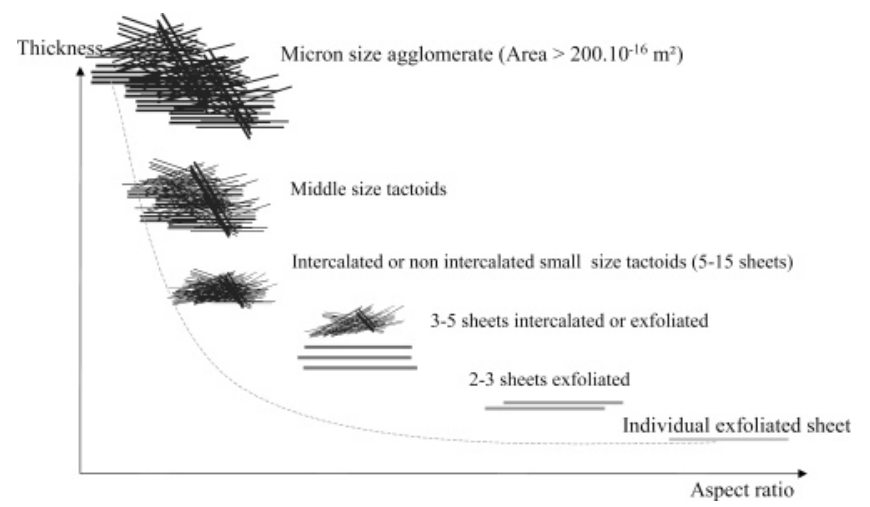

Figure 3. Definition of the different tactoids classes.

estimated $\left(\mu_{\text {agglo } \%}\right)$. The tactoids analyzed from the TEM micrographs were nanotactoids; the average area covered by them was called $A_{\text {nanoexp }}$. We experimentally chose that the nanotactoids had to cover an area less than $2 \times 10^{-14} \mathrm{~m}^{2}$ (smallest area which can be accurately measured by TEM at the lowest chosen magnification), the larger tactoids being called micron size agglomerates. If we assume that the volume ratio occupied by the tactoids in the matrix is equivalent to their surface ratio on the TEM projection micrograph (this assumption is based on the fact that the ultramicrotomic cut have similar thicknesses, about $\approx 60 \mathrm{~nm}$ ), we can define the theoretical tactoids area ratio $A_{\text {theo }}$ as

$$
A_{\text {theo }}=\frac{\frac{w}{\rho_{\text {clay }}}}{\frac{w}{\rho_{\text {clay }}}+\frac{1-w}{\rho_{\text {mat }}}}
$$

where $w$ is the unmodified clay average weight measured by thermogravimetry analysis, $\rho_{\text {clay }}$ is the specific density of the montmorillonite (depending of the inorganic proportion contained in the interlayer $\approx 1.6 \mathrm{~g} / \mathrm{cm}^{3}$ with $30 \%$ inorganic, up to 2.83 for individual clay sheet ${ }^{34}$ ), and $\rho_{\text {mat }}$ is the specific density of the matrix $\left(\approx 0.9 \mathrm{~g} / \mathrm{cm}^{3}\right.$ in our case). Then, an estimation of the amount of micron size agglomerates would be defined as

$$
\mu_{\text {agglo } \%}=\frac{A_{\text {theo }}-A_{\text {nanoexp }}}{A_{\text {theo }}}
$$

Note that in some cases, when there are micron size agglomerates, it is also possible to evaluate and check the amount $\mu_{\text {agglo\% }}$ via optical microscopy observations, this time by directly comparing $A_{\text {agglo }}$ to $A_{\text {theo. }}$. Other results obtained in similar studies, not shown here, emphasize a good correlation between $\mu_{\text {agglo } \%}$ obtained from transmission electron microscopy and optical microscopy image analysis.

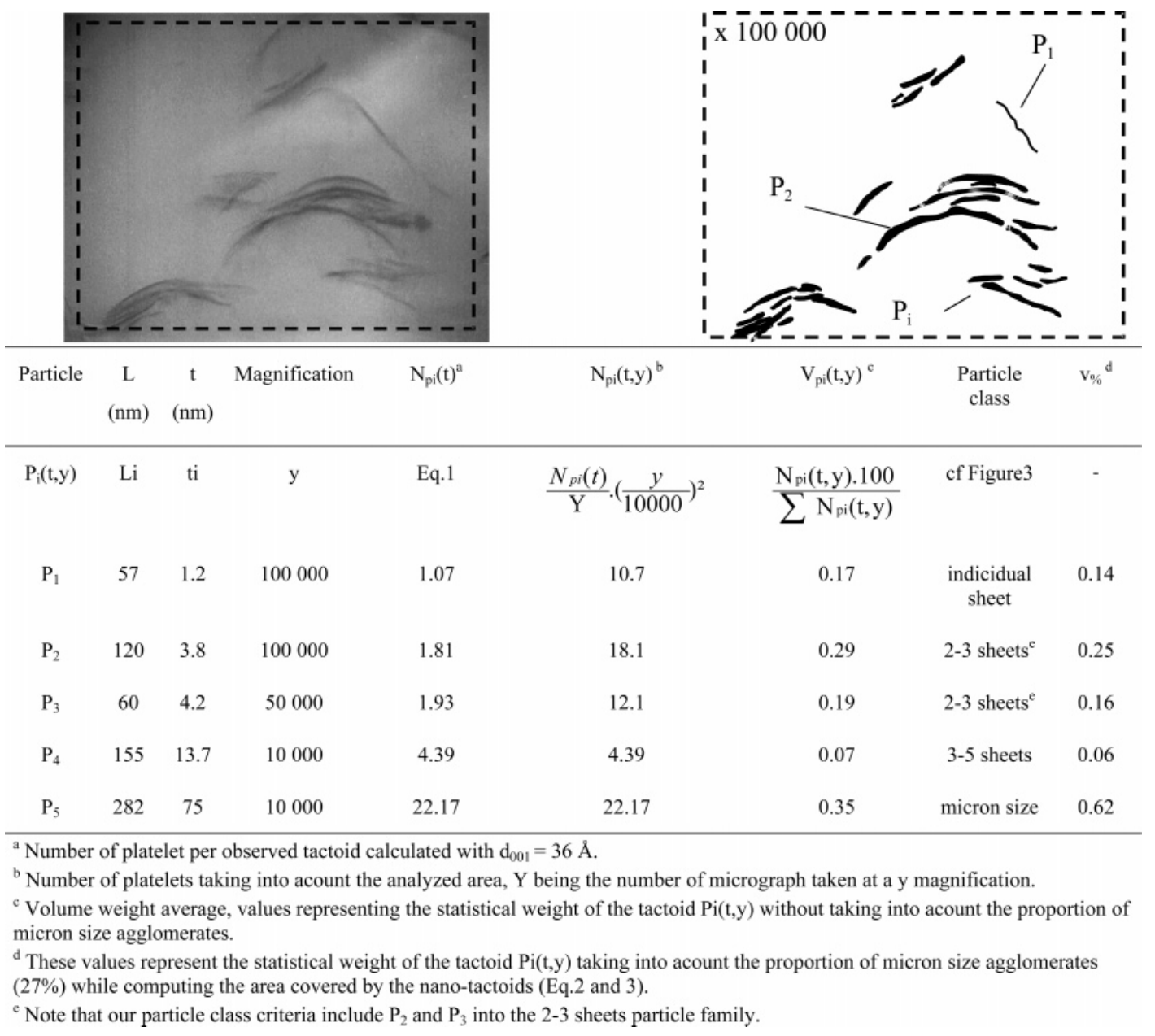

Figure 4. Image analysis detailed procedure. 


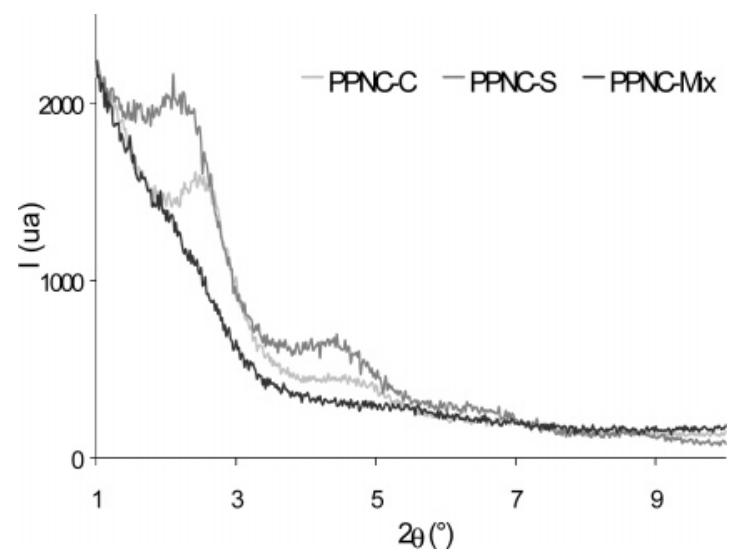

Figure 5. WAXD analysis of polypropylene nanocomposites as a function of the shearing conditions: PPNC-C (carrying screw profile), PPNC-S (shearing screw profile), and PPNCMIX (optimized screw profile).

This last parameter allowed us to describe and accurately compare systems containing different amounts of micron size agglomerates, which is typically the case of mixed intercalated/exfoliated structures. According to the different corrections described earlier, we could attribute a global weight and compute for each class a thickness average $\langle t\rangle$, length average $\langle L\rangle$, aspect ratio average $\langle A R\rangle$, interparticular distance $\left\langle\epsilon_{\|}\right\rangle$or $\left\langle\epsilon_{\perp}\right\rangle$, and average particle density per $\mu \mathrm{m}^{2}$.

An example of the image analysis procedure is given in Figure 4. The main difficulties encountered in this procedure, apart from the deformation induced during the cut, concern the large variations of the shapes of the tactoids in non-fully exfoliated nanostructures, which leads to nonobvious geometrical bounds, as discussed in other papers. ${ }^{34}$

\section{Results and Discussion}

Analysis of Dispersion by WAXD Measurements at the Layer Scale. The diffractograms reported in Figure 5 exhibit information on the dispersion state at the scale of the layers stacking. When only carrying is favored along the screw (PPNC-C), the diffractogram reveals intercalation peaks at $2 \theta$ around $2.5^{\circ}$, which corresponds to an interlayer distance of $36 \AA$. This is very similar to the initial interlayer distance of the clay. When using a single-screw profile, some nanoclays are not intercalated by the polymer matrix despite favorable interactions induced by the PPgMA.

On the other hand, when only shearing is favored along the screw (PPNC-S), the diffractogram reveals an intercalated morphology. The diffraction peak is shifted toward lower angles corresponding to an interlayer distance of $40 \AA\left(\Delta d_{001}=4 \AA\right)$. An intensive shear stress favors the intercalation of polymer chains in the interlayer space.

Only the materials processed with the optimized screw profile shows a flat diffraction pattern without peak characteristic of stacked clay crystalline structure. At this scale, the optimized screw profile seems to reach the best dispersion state.

Evaluation of the Morphology by Rheological Measurements. The viscosity (Figure 6) depends on both the mechanical work performed by the screw and the dispersion state of nanofillers in melt matrix. Nanocomposite compounds processed with NC screw profile shows a rheological behavior very different from the two others, with a higher viscosity at lower shear

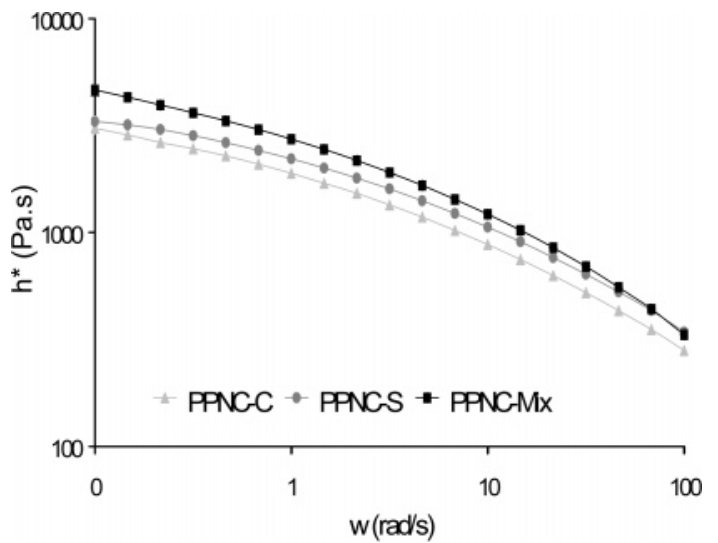

Figure 6. Complex viscosity curves of PPNC-C, PPNC-S, and PPNC-MIX polypropylene nanocomposites.

rate. This viscosity increase is related to the macromolecular chains hindrance by nanoplatelets dispersed in melt medium. With similar chemical interactions, more effective is the mechanical working of screw, better is the dispersion of the nanofillers in the melt matrix, and higher is the compound viscosity at low frequencies. The increasing order of compounds viscosity at low frequency lets one class the compounds as a function their dispersion state. Thus, it is concluded from the rheological measurements that the worst dispersion state is obtained for PPNC-C and the best one for PPNC-MIX. Simultaneously, the slopes of viscoelastic moduli $\left(G^{\prime}\right.$ and $\left.G^{\prime \prime}\right)$ at low frequencies are low and significant of nanocomposite behavior. ${ }^{37}$

Structure and Dispersion by Image Analysis. In the TEM micrographs (Figure 7) at low magnification, all the nanocomposites exhibit quite the same dispersion. At higher magnifications, $\times 50000$ and $\times 100000$, one can better see the differences of structure and clay organization in the matrix. The PPNC-C nanocomposite shows good dispersion and orientation of the clay sheets, whereas PPNC-S contains larger size tactoids with an eyelash shape. Last, the nanocomposite elaborated with the optimized carrying and shearing profile (PPNCMIX) seems to contain well-dispersed and intermediate size tactoids. Thus, if we only consider the TEM observations, we would conclude that the carrying profile is the optimized profile.

Now let us consider the parameters extracted from the TEM image analysis, summarized in Table 2. The statistical study is performed here over a large number of entities. In Figure 8 we compare the frequency of the different classes of tactoids described earlier (Figure 3).

First, as far as the micron size agglomerate population is concerned (Table 2), the amount of micron size agglomerates estimated for PPNC-C nanocomposite is very large $\left(\mu_{\text {agglo }} \%=51 \%\right)$. In the PPNC-C nanocomposite, it can be noticed that half of the clay introduced leads to micron size agglomerates. In the other nanocomposites this ratio is much smaller $(<30 \%)$. This result is surprising compared to what was observed by TEM, but rather well correlated with optical microscopy observations (Figure 9) and rheogical analysis at low frequencies (Figure 6). Optical microscopy indeed shows a few agglomerates (mean diameter about $0.3 \mathrm{~mm}$ ) in the PPNC-C nanocomposite and none in the other nanocomposites (PPNC-S and PPNC-MIX). Thus, as can be seen in Figure 10, increasing the shearing in the melt state (from PPNC-C to PPNC-S) has for consequence to decrease the average thickness and length of micron 


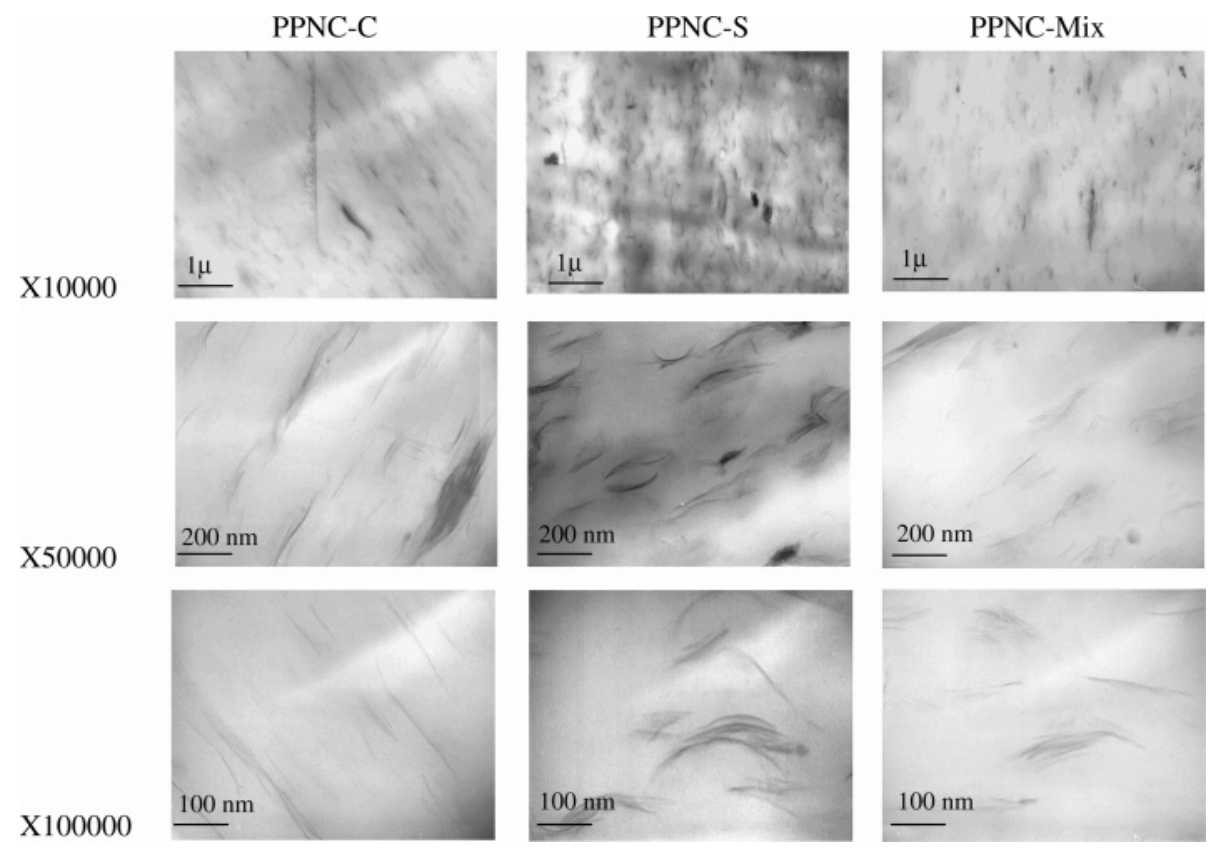

Figure 7. TEM micrographs of PPNC-C, PPNC-S, and NPPNC-S polypropylene nanocomposites.

Table 2. Parameters Extracted from the Image Analysis ${ }^{a}$

\begin{tabular}{ccccccccc}
\hline nanocomposite & no. of analyzed entities & $\mu_{\text {agglo }}(\%)$ & $\langle t\rangle \mathrm{nm}$ & $\langle L\rangle \mathrm{nm}$ & $\langle A R\rangle$ & $\epsilon_{\|}(\mathrm{nm})$ & $\epsilon_{\perp}(\mathrm{nm})$ & particle density per $\mu^{2}$ \\
\hline PPNC-C & $>445$ & 51 & 71 & 400 & 11.8 & 100 & 160 & 58 \\
PPNC-S & $>380$ & 18 & 31 & 182 & 11.8 & 160 & 200 & 60 \\
PPNC-MIX & $>459$ & 27 & 32 & 313 & 13.6 & 170 & 150 & 68
\end{tabular}

${ }^{a} \mu_{\text {agglo }}$ is anestimation of the amount of micronics agglomerates, $\langle t\rangle$ weight-average tactoids thickness, $\langle L\rangle$ weight-average tactoids length, $\langle A R\rangle$ weight-average tactoids aspect ratio, $\left\langle\epsilon_{\|}\right\rangle$interparticular distance in the mean tactoids orientation, and $\left\langle\epsilon_{\perp}\right\rangle$ interparticular distance perpendicular to the mean orientation.

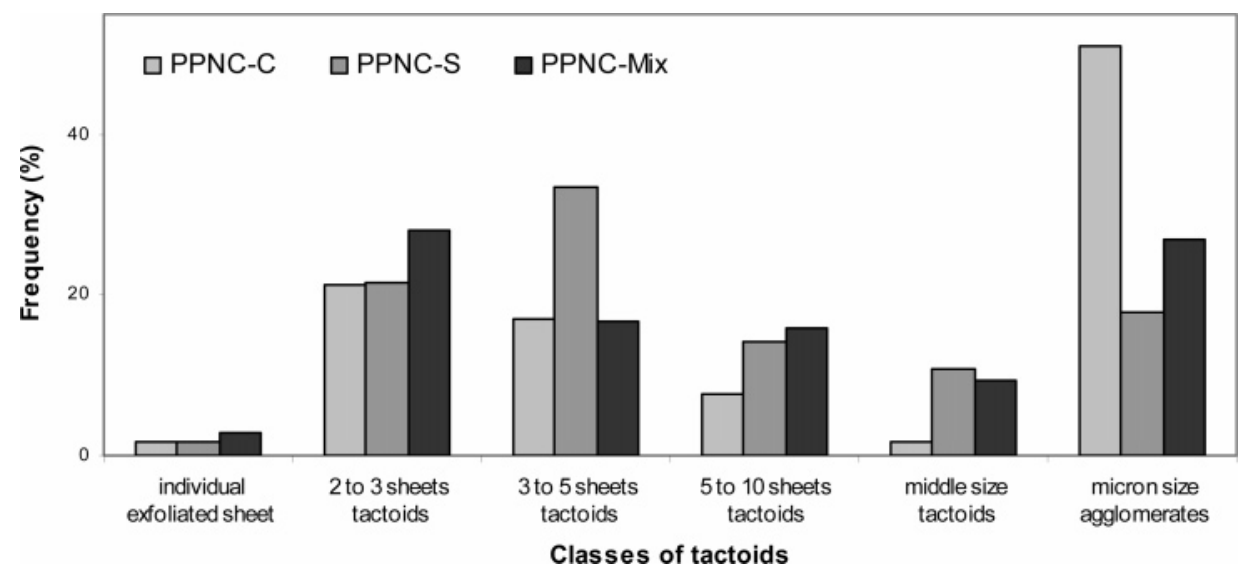

Figure 8. Comparison of the frequency of the different classes of tactoids.

size agglomerates. The shapes of the clay particles (thickness and length) are different and can give insight into the mechanisms of clay exfoliation. In the case of the carrying profile, we assume the diffusion of polymer chains in the interlayer space to be responsible for the tactoids peeling. On the contrary, with the shearing profile, the large stress transfer in the melt breaks the micron size agglomerates into smaller tactoids instead of peeling them into individual sheets.

The PPNC-MIX nanocomposite gives an excellent illustration of both effects (peeling and breaking): increasing the shear/carrying ratio leads to a smaller amount of micron size agglomerates as well as a smaller average thickness and higher average length compared to PPNC-C. Morover, these results can be correlated with the mechanism proposed by Dennis et al. ${ }^{3}$ for the delamination and the dispersion of clay into a polymer during melt processing.

For a second time, let us consider the nanotactoids population. The image analysis results show (Figure 8) that there is a difference of the extent of exfoliation between the nanocomposites PPNC-C and PPNC-MIX and nanocomposite PPNC-S. In fact, the average size of the nanotactoids population measured is not the same and varies from 2 to 3 sheets tactoids for PPNC-C and PPNC-MIX to 3-5 sheets tactoids for PPNC-S. The main morphological change between PPNC-C and PPNCMIX is the proportion of the nanotactoids population, 
PPNC-C

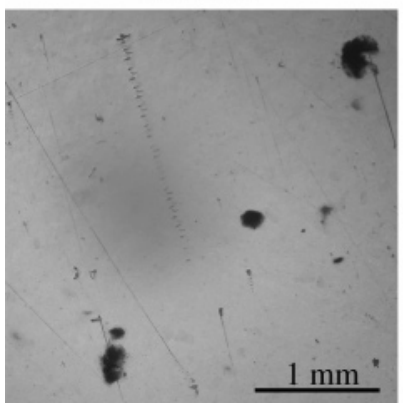

PPNC-S

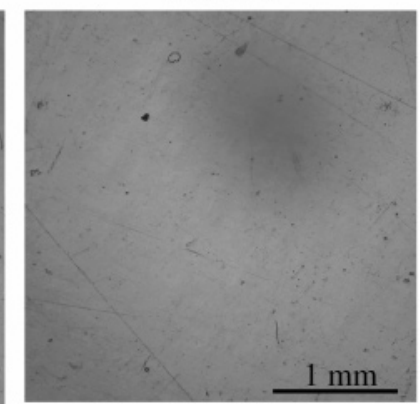

PPNC-Mix

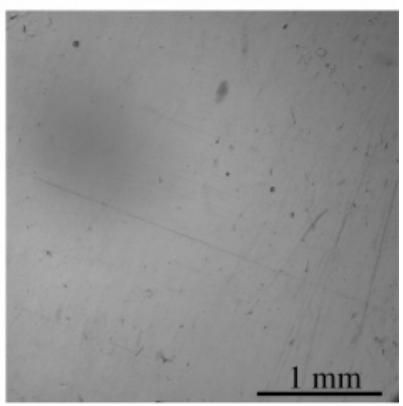

Figure 9. Optical microscopy observations of PPNC-C, PPNC-S, and PPNC-MIX polypropylene nanocomposites.

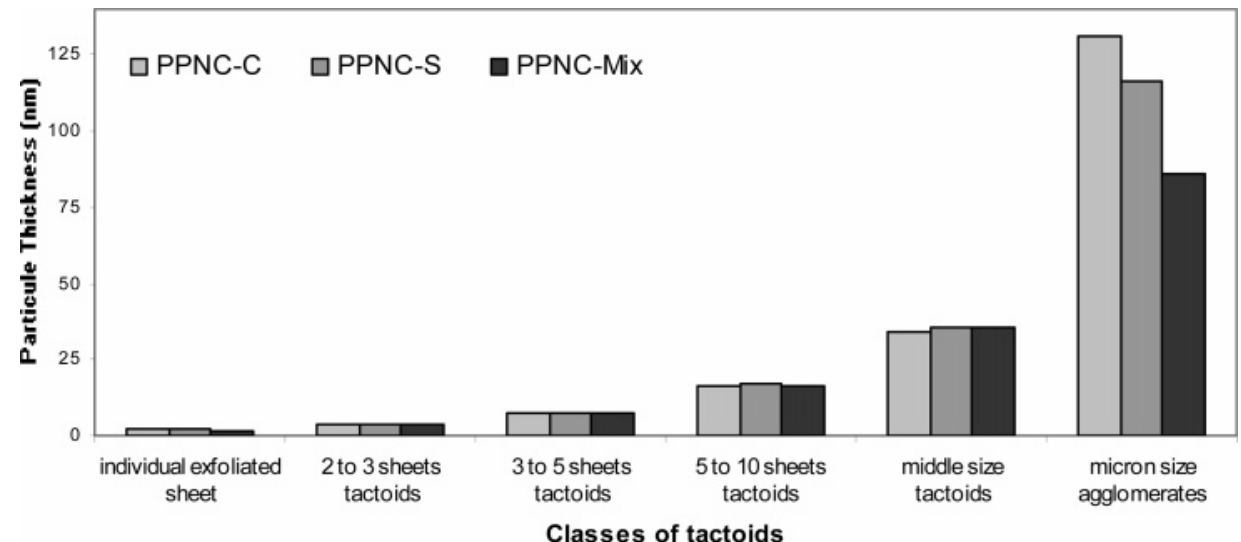

Figure 10. Comparison of the weight-average thickness of the different classes of tactoids.

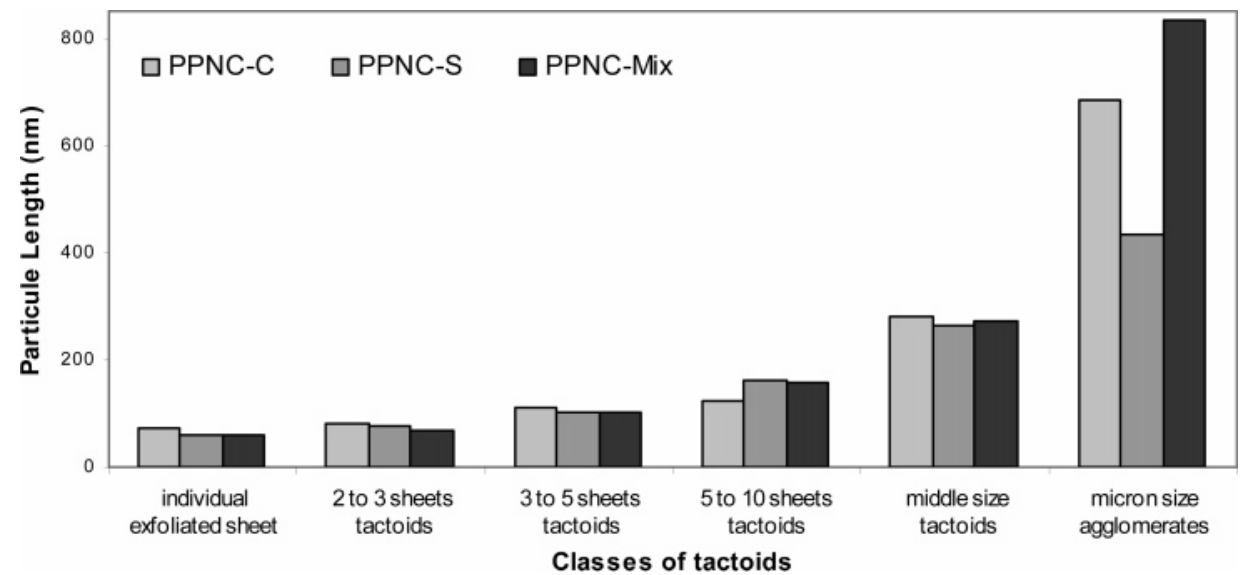

Figure 11. Comparison of the weight-average length of the different classes of tactoids.

which is about $50 \%$ for PPNC-C and about $73 \%$ for PPNC-MIX (Table 2). Moreover, the decreasing of tactoids size with an increasing shear no longer applies for the nanotactoids population (Figures 10 and 11). The analysis shows no significant differences in the thicknesses and lengths of the different classes of tactoids in the three nanocomposites.

Other parameters obtained by image analysis are summarized in Table 2. The changes in the interparticular distances are not significant because of the relatively large incertainty $(\sim 90 \mathrm{~nm})$. The interparticular distance is thus about $160 \mathrm{~nm}$ for all the nanocomposites. The average aspect ratio (Figure 12) of the tactoids is not very high $(<14)$ compared to the theoretical aspect ratio of individual sheets of montmorillonite, even though we are able to identify many exfoliated sheets. The error done when measuring the length during the analysis may come from the assumption of rectilinear sheets on the TEM projection or because the montmorillonite sheets were always cut during the preparation of the microscopy grid by ultramicrotomy. Another explanation could be related to a too large stress transfer during the melt, which breaks the small tactoids; the length measured for the nanotactoids always lied around $100 \mathrm{~nm}$ and not around $500 \mathrm{~nm}$ as expected.

Last, the density of particles calculated is a little improved in the case of the optimized profile MIX. Unfortunately, we are not able to state whether the difference observed in the density of particles is significant or not and whether it will lead to different macroscopic properties. Some recent results obtained by Chavarria et al. ${ }^{34}$ on polyamide- 6 nanocomposites show a density about 550 particles $/ \mu \mathrm{m}^{2}$ with $5 \%$ montmorillonite. Looking at this parameter only, it is obvious that our nanocomposites are poorly exfoliated, since the density of particles is far smaller than that measured by Chavarria et al. 


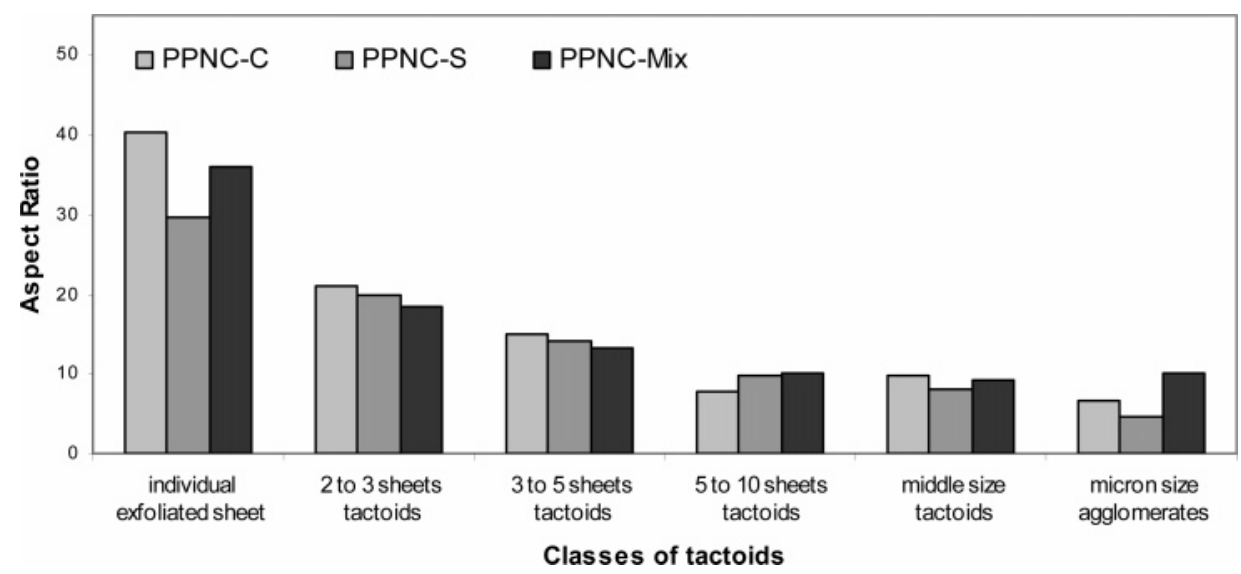

Figure 12. Comparison of the weight-average aspect ratio of the different classes of tactoids.

\section{Conclusion}

To quantitavely describe the dispersion and the exfoliation of montmorillonite sheets in the nanocomposites, an image analysis procedure was developed. The parameters obtained give a lot of pieces of information and allow a very fine description of the microstructure, other than "exfoliated" vs "intercalated" nanocomposites. The average thicknesses, lengths, and aspect ratios of each class of tactoids could be measured as well as their relative proportions and the average distances between two adjacent tactoids. It is important to note that these layered silicate systems could not be reliably described with transmission electron microscopy or wide-angle X-ray diffraction alone. Moreover, optical microscopy observations allowed us to observe large immiscible clay agglomerates which we could not see by TEM because of the too small probed area. Multiscale characterization by other techniques like small-angle $\mathrm{X}$-ray diffusion, TEM image analysis, optical microscopy, melt viscosity, etc., are compulsory to understand the mechanism of dispersion and properties enhancement.

The image analysis procedure was used to characterize the dispersion and the exfoliation states of clay in a polypropylene matrix. Three different profile designs were used to elaborate the nanocomposites. The results by image analysis show the key role of the screw profile design on the final morphology of the nanocomposites. Increasing the shear in the melt will lead to a decrease of the proportion of micron size agglomerates. It has also a negative effect on the lengths and aspect ratios of the other tactoids. So far, a screw design combining both shearing and carrying can lead to nanocomposites with a significantly weaker amount of micron size agglomerates and a preserved aspect ratio. This was a crucial step to obtain real nanocomposites (i.e., with a reduced amount of micron size agglomerates). Yet, work has still to be done to fully exfoliate montmorillonite platelets.

Acknowledgment. This work was funded by the POLYLAM consortium and the Rhône Alpes Region. The authors thank Multibase Dow Corning for the development of the different screw designs. The Centre Technologique des Microstructures of the Université Lyon I (Lyon, France) is also thanked for the access to the cryoultramicrotomes.

\section{References and Notes}

(1) Alexandre, M.; Dubois, P. Mater. Sci. Eng. 2000, 28, 1-63.

(2) Kato, M.; Usuki, A. In Polymer-Clay Nanocomposites, John Wiley \& Sons: New York, 2000; pp 97-109.

(3) Dennis, H. R.; Hunter, D. L. Chang, S.; Kim, J. L.; White, J. W.; Cho, Paul, D. R. Polymer 2001, 42, 9513-9522.

(4) Ray, S. S.; Okamoto, M. Prog. Polym. Sci. 2003, 28, 15391641.

(5) Su, S.; Wilkie, C. A. Polym. Degrad. Stab. 2004, 83, 347362.

(6) Wang, S.; Hu, Y.; Zhongkai, Q.; Wang, Z.; Chen, Z.; Fan, W. Mater. Lett. 2003, 57, 2675-2678.

(7) Gopakumar, T. G.; Kontopoulou, J. A.; Parent, J. S. Polymer 2002, 43, 5483-5491.

(8) Liu, L.; Zongneng, Q. I.; Xiaoguang, Z. J. Appl. Polym. Sci. 1999, 71, 1113-1138.

(9) Liang, Z. M.; Yin, J.; Xu, H. J. Polymer 2002, 44, 1391-1399.

(10) Yang, Y.; Zhu, Z. K.; Yin, J.; Wang, X. Y.; Qi, Z. E. Polymer 1999, 40, 4407-4414.

(11) Kawasumi, M.; Hasegawa, N.; Kato, M.; Usuki, A.; Okada, A. Macromolecules 1997, 30, 6333.

(12) Maiti, P.; Nam, P. H.; Okamoto, M.; Hasegawa, N.; Usuki, A. Macromolecules 2002, 35, 2042-2049.

(13) Zhang, J.; Wilkie, C. A. Polym. Degrad. Stab. 2003, 80, 163169.

(14) Zhang, Y. Q.; Lee, J. H.; Jang, H. J.; Nah, C. W. Composites, Part B 2004, 35, 133-138.

(15) Beyer, F. L.; Tan, N. C. B.; Dasgupta, A.; Galvin, M. E. Chem. Mater. 2002, 14, 2983.

(16) Nam, P. H.; Maiti, P.; Okamoto, M.; Kotaka, T.; Hasegawa, N.; Usuki, A. Polymer 2001, 42, 9633-40.

(17) Maiti, P.; Nam, P. H.; Okamoto, M.; Kotaka, T. Polym. Eng. Sci. 2002, 42, 1864-1871.

(18) Koo, C. M.; Ham, T. H.; Kim, S. O.; Wang, K. H.; Chung, I. J. Macromolecules 2002, 25, 5116-5122.

(19) Wagener, R.; Reisinger, T. J. G. Polymer 2003, 44, 75137518.

(20) Garcia-Lopez, D.; Picazo, O.; Merino, J. C.; Pastor, J. M. Eur. Polym. J. 2003, 39, 945-950.

(21) Morgan, A. B.; Gilman, J. W. J. Appl. Polym. Sci. 2003, 1329.

(22) Bafna, A.; Beaucage, G.; Mirabella, F.; Mehta, S. Polymer 2003, 44, 1103-1115.

(23) Masenelli-Varlot, K.; Reynaud, E.; Vigier, G.; Varlet, J. J. Polym. Sci., Part B: Polym. Phys. 2001, 40, 272-283.

(24) Varlot, K.; Reynaud, E.; Kloppfer, M. H.; Vigier, G.; Varlet, J. J. Polym. Sci., Part B Polym. Phys. 2001, 39, 1360-1370.

(25) Krishnamoorti, R.; Yurekli, K. Curr. Opin. Colloid Interface Sci. 2001, 6, 464.

(26) Incarnato, L.; Scarfato, P.; Scatteia, L.; Acierno, D. Polymer 2004, 45, 3487-3496.

(27) Burgentzlé, D.; Duchet, J.; Gérard, J. F.; Jupin, A.; Fillon, B. J. Colloid Interface Sci. 2004, 278, 26-39.

(28) Pluart, L. L.; Duchet, J.; Sautereau, H.; Halley, P.; Gerard, J. F. Appl. Clay Sci. 2004, 25, 207-219.

(29) Degrange, J. M.; Masenelli-Varlot, K.; Vigier, G.; Mathieu, O.; Varlet, J. proceedings of the $11^{\text {th }}$ European Conference on Composite Materials, Rhodes, Greece, 2004. 
(30) VanderHart, D. L.; Asano, A.; Gilman, J. W. Macromolecules 2001, 34, 3819

(31) VanderHart, D. L.; Asano, A.; Gilman, J. W. Chem. Mater. 2001, 13, 3796.

(32) Ranade, A.; D’Souza, N. A.; Gnade, B. Polymer 2002, 43, 3759-3766.

(33) Marchant, D.; Jayaraman, K. Ind. Eng. Chem. Res. 2002, 41, 6401-6408.

(34) Chavarria, F.; Paul, D. R. Polymer 2004, 45, 8501-8515.

(35) Fornes, T. D.; Paul, D. R. Polymer 2003, 44, 4993-5013.
(36) Boucard, S.; Duchet, J.; Gérard, J. F.; Prele, P.; Gonzalez, S. Macromol. Symp. 2002, 194, 241-246.

(37) Boucard, S.; Duchet, J.; Prele, P.; Bayet, A.; Gérard, J. F., to be published.

(38) Bayet, A.; Prele, P.; Boucard, S. In INPI. Multibase S.A.; Vol. 0209509; France 26 Juillet, 2002, p 53.

(39) van Es M. Ph-D thesis, TU Delft, 2001.

MA051249+ 